\title{
Making the Nuss repair safer: Use of a vacuum bell device
}

\author{
Varun Puri, MD, MSCI \\ From the Department of Surgery, Washington University in St Louis, Mo. \\ Disclosures: Author has nothing to disclose with regard to commercial support. \\ Received for publication Aug 23, 2015; accepted for publication Aug 24, 2015; available ahead of print Sept 19, \\ 2015. \\ Address for reprints: Varun Puri, MD, MSCI, Washington University School of Medicine, Division of Cardiotho- \\ racic Surgery. Campus Box 8234, 660 S Euclid Ave, St Louis, MO 63110 (E-mail: puriv@wudosis.wustl.edu). \\ J Thorac Cardiovasc Surg 2015; 150:1374-5 \\ 0022-5223/\$36.00 \\ Copyright (c) 2015 by The American Association for Thoracic Surgery \\ http://dx.doi.org/10.1016/j.jtcvs.2015.08.086
}

Dr Elsayed from Ain Shams University in Cairo reports a novel modification of the crane technique for Nuss repair in pectus excavatum. ${ }^{1}$ The author describes a technique using a vacuum bell to anteriorly elevate the sternum using negative pressure and open up the retrosternal space to allow safer passage of the metal bar introducer that guides the Nuss bar. This incisionless approach represents a useful advancement over the more invasive original crane technique that requires the placement of a sternal wire and a metallic lifting device via an incision.

Although the debate between the proponents of the Nuss and the Ravitch procedures for pectus excavatum is unlikely to be settled in the foreseeable future, it is clear that surgeons generally perform one or the other exclusively in their practice. The short-term advantages of the Nuss procedure include smaller incisions and less pain in the correction of an anatomic abnormality that is often a significant cosmetic problem. The major drawback, and likely a deterrent to the wider adoption of the Nuss procedure, is the relatively blind passage of metallic instrumentation between the pericardium and the posterior table of the sternum. Although the reported incidence of cardiac perforation is rare, published literature may not be capturing all such events. Any technique that improves access and visualization during a step of the operation potentially associated with catastrophic complications is likely to be enthusiastically received by the surgeons who perform the Nuss. This is especially true if the technical modification does not require additional incisions, can be performed relatively quickly, and does not add significantly to the expense of the operation. The current technique meets all of these criteria. It also has the added advantage of at least subjectively making an anxiety-provoking step of the operation safer.

Improving surgical access when performing minimally invasive procedures in the coelomic cavity can be achieved by gas insufflation or using gasless techniques of displacing the body wall away from the viscera. Gasless or "lift" laparoscopy was a realistic alternative to carbon dioxide insufflation in the early days of laparoscopic surgery. The

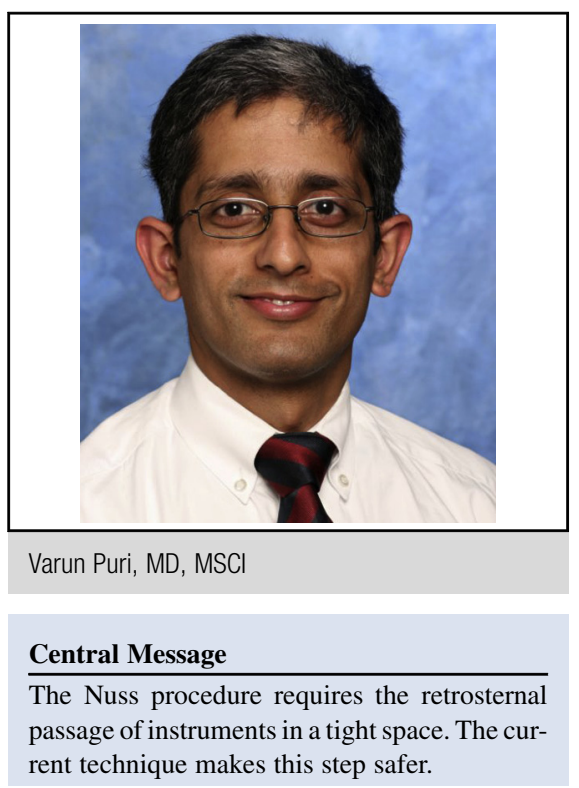

See Article page 1372 .

reported advantages to gasless techniques include the ability to use conventional surgical instruments, seamless use of suction during the operation, and avoidance of complications such as pneumothorax and gas embolism. However, with improved instrumentation and increasing experience in the surgical community, carbon dioxide insufflation has become the dominant technique facilitating laparoscopic access. ${ }^{2}$ Video-assisted thoracoscopic procedures have less commonly used carbon dioxide insufflation because of our ability to deflate the lungs to improve visualization and the inability of low-pressure gas to expand the rigid thoracic cage. "Lift" techniques for thoracic procedures have been described though, predominantly for anterior mediastinal operations, and the most well-known example is the use of the Cooper retractor for transcervical thymectomy. ${ }^{3}$ Other than the adverse effects described by the author, the only other potential disadvantage to the present technique is the small amount of additional time it would take to take down the vacuum bell if an emergency sternotomy is necessary.

Generating objective evidence for the added safety from this modification of the crane technique is likely to require hundreds of cases. In the interim, it would be interesting to see the Ain Shams University team and potentially other collaborating sites continue to report on cumulative case 
series to document the efficacy of the procedure and share technical pearls gained with experience.

\section{References}

1. Elsayed H. Crane technique with the vacuum bell device for improving access in the Nuss procedure. J Thorac Cardiovasc Surg. 2015;150:1372-3.
2. Ren H, Tong Y, Ding XB, Wang X, Jin SQ, Niu XY, et al. Abdominal wall-lifting versus $\mathrm{CO} 2$ pneumoperitoneum in laparoscopy: a review and meta-analysis. Int $J$ Clin Exp Med. 2014;7:1558-68.

3. Cooper JD, Al-Jilaihawa AN, Pearson FG, Humphrey JG, Humphrey HE. An improved technique to facilitate transcervical thymectomy for myasthenia gravis. Ann Thorac Surg. 1988;45:242-7. 